\title{
LIMIT STRENGTH OF THE REINFORCED CONCRETE ROTARY KILN SUPPORTS UNDER TIME-VARIABLE LOAD
}

\author{
J. Zachwieja*
}

\begin{abstract}
The study discusses the issues of resistance of reinforced concrete support for a clinker rotary kiln under the constraints of deformation of a rotary drum shell due to thermal impact of the kiln feed on a refractory lining and thus the rotary drum shell. The frequency of support vibrations is low and similar to the rotation frequency of the rotary drum. Any deformation of the shell results in incorrect operation of the open gear which is a component of the rotary kiln drive. It is a kinematic pair consisting of a toothed ring, mounted on the rotary drum shell and a pinion coupled via a flexible coupling with an output shaft of a reduction gear. The frequency of those constraints is higher, similar to the open gear mesh frequency. Variable clearance, both inter-teeth and tip clearance, mainly due to synchronous precession of the toothed ring and wear of the meshing teeth surface induces the rotary drum vibrations, which are transferred to the support via a ring - roller system.
\end{abstract}

Keywords: support vibrations, constraint frequency, synchronous precession, fatigue limit, low and high-cycle loading

\section{Introduction}

Concrete, unlike steel, is a structural material with a significantly lower mechanical strength, in particular to the time-variable loads due to the progressive deterioration of adhesion between an aggregate and a cement phase.

Fatigue limit of concrete used in load-bearing structures for machines generating high-amplitude and high-frequency time-variable loads is a considerable problem (Comelissen, 1986).

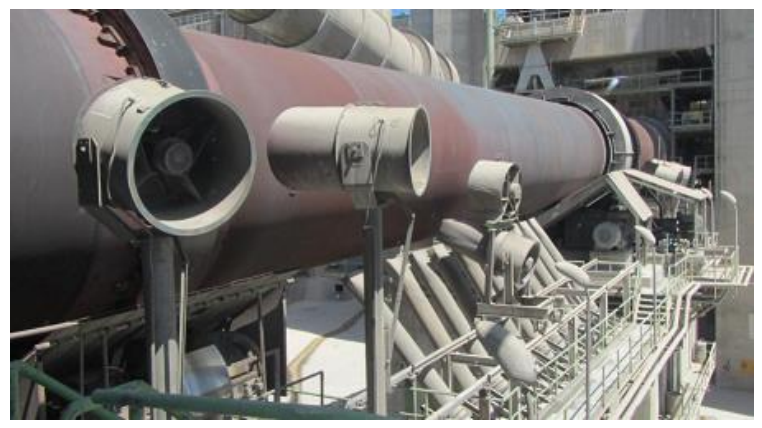

Fig. 1: Sintering zone in the rotary kiln with an open gear.

Concrete structures are usually reinforced with steel to increase their load capacity. Ductility of the reinforcing steel has an enormous effect on structural safety after the permissible loads are exceeded. The cement kiln supports are in particular subjected to variable loads. Exceeding the permissible loads in concrete structures reinforced with low-ductility steel results in brittle cracking of the reinforcement bars, which in turn may lead to structural damage at low strain and low concrete surface cracking. High ductility steel, by transferring stresses exceeding its yield point will yield and increase the structure's

* Assoc. Professor Janusz Zachwieja, PhD., Department of Applied Mechanics, University of Technology and Life Sciences in Bydgoszcz (Poland), Kaliskiego 7, Bydgoszcz; PL, janusz.zachwieja@utp.edu.pl 
susceptibility to deformation. The ultimate strength is exceeded at high strain and visible cracking of the concrete surface. Thus, it is reasonable to use high-strength and high-ductility steel as a reinforcement.

\section{Strength of the reinforced concrete structures to low-frequency loads}

A fatigue limit of high-strength concrete is a crucial factor that affects the design of industrial structures subject to time-variable loads. A system of this type is subject to low-cycle ( $\mathrm{N}<10^{3}$ cycles) and highcycle $\left(\mathrm{N}>10^{3}\right.$ cycles) fatigue loads, usually characterized by low frequency and cycle asymmetry (Hsu 1981). It requires a thorough knowledge of the nature of the material behaviour under cyclically variable loads. Several models based on a linear and elastic mechanics of cracking (Bazant and Shell, 1991) and failure mechanics (Gao and Hsu, 1998) have been developed.

In accordance with the relevant standards, the requirements for structures under cyclic loads are limited to the condition that the fatigue damage to the concrete due to cyclic loading must not exceed the allowable values $\sigma_{c}$, expressed as follows:

$$
\max \left(\sigma_{c}\right)<0.25 \sigma_{c}^{\text {stat }}
$$

where: $\sigma_{c}^{\text {stat }}$ - allowable compressive stress under static load.

The analysis included a rotary kiln which required an audit due to the noticeable vibrations of its supports. The measurements showed that the deflection of the rotary drum shell near the support adjacent to the drive was $\sim 40 \mathrm{~mm}$. Load due to rotary drum deflection resulted in a $16 \mathrm{MPa}$ stress (Fig. 2a) in the lower section of the reinforced concrete support. The stress can be transferred by the structure. The stresses were accumulated around the frame supporting the rotary kiln rollers. If the operation of the drive is uniform and the support elements are symmetrical in relation to the symmetry plane of the support, the reinforced concrete slab is a compression member.
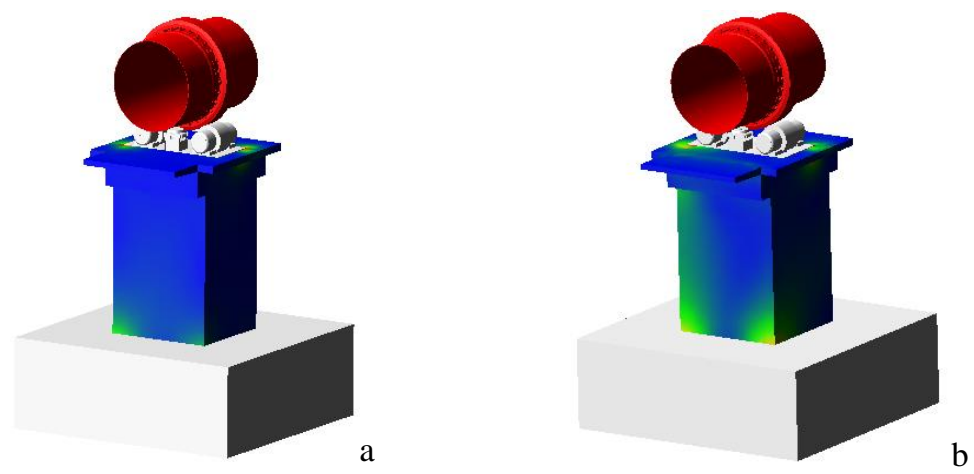

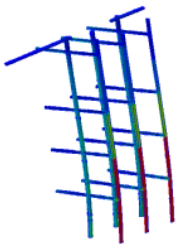

$\mathrm{c}$

Fig. 2: a) Stress distribution in the support section under static-compressive load. b) Stress distribution in the support section under compressive load and support bending load. c) Stress distribution in the reinforcement bars under compressive load and support bending load.

The situation is different if the rotary drum shell is bent due to incorrect operating conditions. Loss of the refractory lining used as a thermal protection of the kiln shell may cause not only local deformations of the rotary drum shell but also bending of the tube at a long section between the supports. As a result, the stresses in the support sections may increase to $40 \mathrm{MPa}$ (Fig. 2b). Combined with a high tube curvature, the rollers may lose contact with the rolling ring. In one turn of the kiln, the reinforced concrete support is alternatively loaded and unloaded with a compressive force and simultaneously bent during deflection.

The reinforcement bars contribute to the transfer of loads in sections where the stresses are significantly higher than in the concrete. It is a correct state, since the tensile strength of concrete is low. Fig. 2c shows stress distribution in the reinforcement bar sections. 


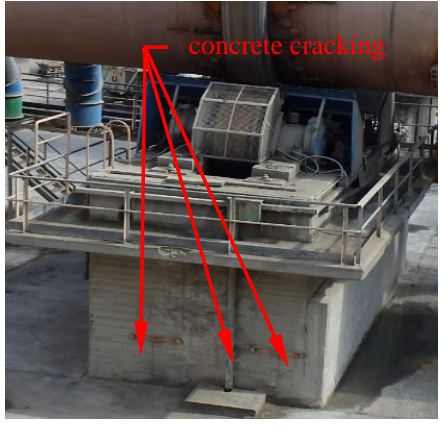

a

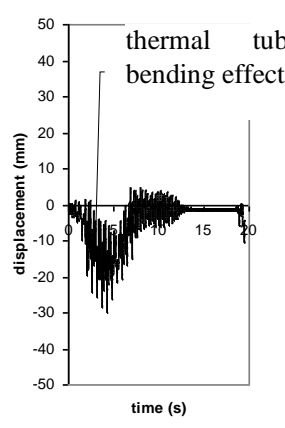

b
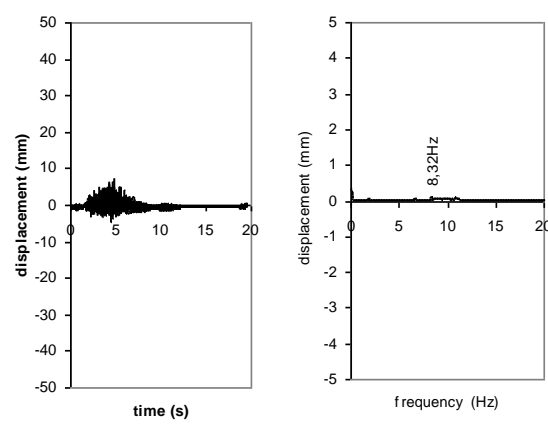

$\mathrm{c}$

Fig. 3: Kiln support with visible fatigue cracks. Time characteristics and spectrum of the support vibrations: a) in a plane perpendicular to the rotary drum axis; $b$ ) in a vertical plane.

Fig. $3 \mathrm{~b}$ and $3 \mathrm{c}$ show differences in support deformation at compression and bending. The compressive load cause up to $4 \mathrm{~mm}$ deformation, whereas bending may cause $26 \mathrm{~mm}$ deflection of the support. The vibration frequency of the support in a plane perpendicular to the rotary drum axis is $0.1 \mathrm{~Hz}$. Fig. 3a shows the results of superposing the effects of the thermal deformation of the rotary drum in form of scratches and cracks in the support.

\section{Resistance of the reinforced concrete structures to high-frequency loads}

The rotary kiln drum (Fig. 4) is driven by a main motor (1), a reduction gear (2) and an open gear including a pinion (3) and a toothed ring mounted on a rotary drum shell (4). Table 1 shows the operating parameters of the kiln.

2

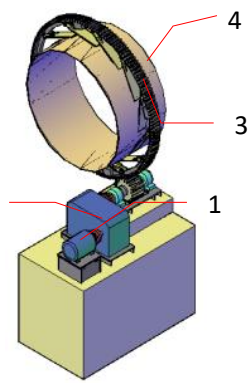

Fig. 4: Drive unit of the rotary kiln.

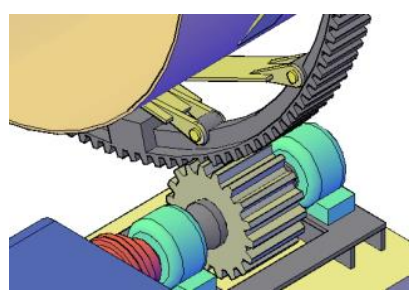

Fig. 5: Meshing surface: a) pinion, b) toothed ring.

Wear (pitting) can be observed at the pinion and the toothed ring surfaces due to large thrust and interaction between the meshing gear surface (Fig. 5).

Tab. 1: $\quad$ Structural and operating parameters of the rotary kiln.

\begin{tabular}{lclc}
\hline operating speed & $3.35 \mathrm{~min}^{-1}$ & the number of teeth of the wreath & 148 \\
\hline motor power & $470 \mathrm{kV}$ & the number of teeth of the pinion & 28 \\
\hline open gear ratio & $1: 5.286$ & number of rings & 3 \\
\hline gear module - open gear & $39 \mathrm{~mm}$ & ring diameter (external) & $5348 \mathrm{~mm}$ \\
\hline roller diameter & $1800 \mathrm{~mm}$ & ring diameter (internal) & $4581 \mathrm{~mm}$ \\
\hline
\end{tabular}

Incorrect operation of the open gear due to variable tip clearance between the toothed ring and the pinion induces vibrations resulting in 140 streaks, evenly distributed around the periphery at the face of the ring. The depth of the streaks is $\sim 0.02 \mathrm{~mm}$ (Fig. 6). Tip clearance for a $39 \mathrm{~mm}$ module should be $7.8-11.7 \mathrm{~mm}$. The clearance variability may be due to misaligned ring mounting on the rotary drum shell or the thermal bending of the tube. Table 2 shows the measured clearance as a function of temperature. 


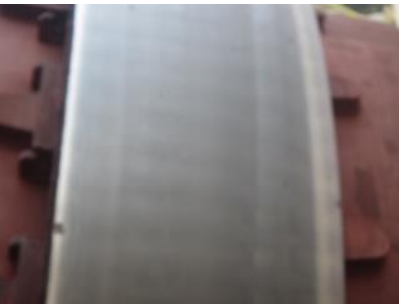

Tab. 2: The tip clearance as a function of ring temperature.

\begin{tabular}{|c|c|c|}
\hline temperature & $\begin{array}{c}\text { clearence } \\
\text { min. }\end{array}$ & $\begin{array}{c}\text { clearence } \\
\text { max. }\end{array}$ \\
\hline $283^{0} \mathrm{~K}$ & $9.2 \mathrm{~mm}$ & $12.1 \mathrm{~mm}$ \\
\hline $298^{0} \mathrm{~K}$ & $10.5 \mathrm{~mm}$ & $16.8 \mathrm{~mm}$ \\
\hline $368^{0} \mathrm{~K}$ & $14.7 \mathrm{~mm}$ & $22.2 \mathrm{~mm}$ \\
\hline
\end{tabular}

Fig. 6: The arrangement of streaks on the side surface of the ring.

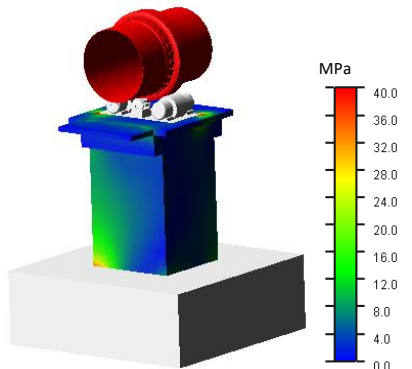

Fig. 7: Stress distribution in the support section under high-frequency load.

Measurements and analysis of the nature of vibrations measured in the induction zone of the open gear indicate a strong beat due to interference of two signals with similar frequency. The amplitudes of those signals are also similar. The vibrations were analysed based on the measured time characteristics for the rotary drum speed: $3.35 \mathrm{RPM}$, corresponding to the gear mesh frequency: $8.26 \mathrm{~Hz}$. Based on the number of streaks (140), $7.87 \mathrm{~Hz}$ frequency shall be generated. Transfer of the vibrations to the support will increase stresses in the support sections both at its base and at the platform (Fig. 7). The stresses in the support sections will exceed $40 \mathrm{MPa}$, which is close to the allowable stress for concrete.
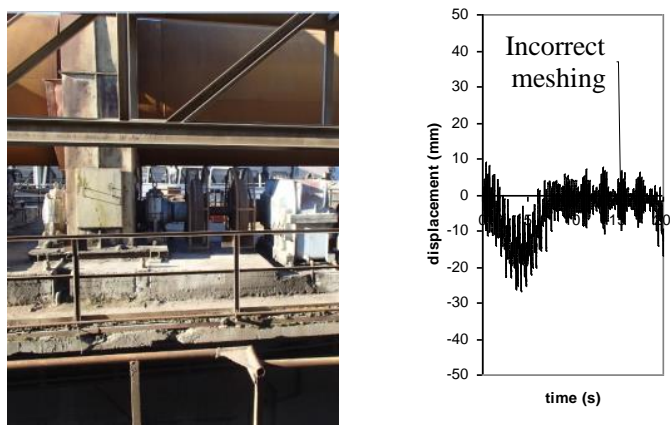

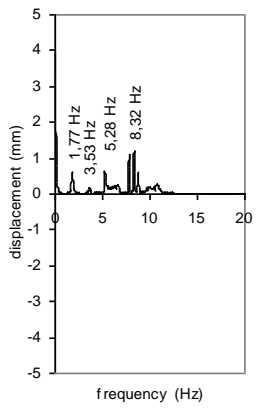

b
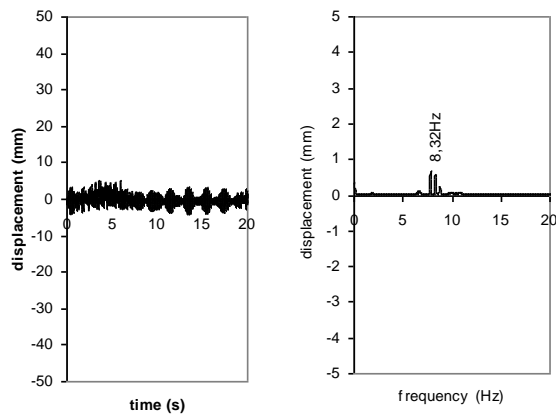

Fig. 8: Support damage: a) time characteristics and spectrum of the support vibrations in the plane perpendicular to the rotary drum axis. b) time characteristics and spectrum of the support vibrations in the vertical plane.

Vibrations at the gear mesh frequency and the frequency due to the number of streaks on the rotary drum surface is a significant constraint for the reinforced concrete support at $\sim 8 \mathrm{~Hz}$. Fig. 8 shows the support damage near the open gear and the drive.

\section{Conclusions}

Despite the fact that the thermal bending of the tube resulting in a variable thrust of the roller ring on the rollers will increase the vibration amplitude more than the constraint induced by the changing mesh clearance, the latter poses a greater hazard to the durability of the support, due to the higher frequency of the constraint. Concrete as a structural material is very sensitive to this type of load and to eliminate its impact, the rotary drum may require straightening or at least correcting the alignment between the ring and the shell.

\section{References}

Bazant, Z. and Schell, W. (1993) Fatigue Fracture od High-Strength Concrete and Size Effect. ACI Materials Journal, V.90, No. 5, Sept-Oct.

Comelissen, H.A. (1986) State of art report on fatigue of plain concrete. Delf University of Technology, Report 586-3, Research Nr 7804, Delf.

Gao, L. and Hsu, T. T. C. (1998) Fatigue of Concrete Under Uniaxial Compression Cyclic Loading. ACI Materials Journal, V.95, No. 5, Sept-Oct.

Hsu, T. T. C. (1981) Fatigue od Plain Concrete. ACI Journal, No. 4, Jul-Aug. 